\title{
Anti-Interleukin- 6 Monoclonal Antibody Induces Regression of Human Prostate Cancer Xenografts in Nude Mice
}

\author{
Peter C. Smith ${ }^{1}$ and Evan T. Keller ${ }^{1,2,3,4 *}$ \\ 'Unit for Laboratory Animal Medicine, University of Michigan, Ann Arbor, Michigan \\ ${ }^{2}$ Department of Pathology, University of Michigan, Ann Arbor, Michigan \\ ${ }^{3}$ Connective Tissue Oncology, University of Michigan, Ann Arbor, Michigan \\ ${ }^{4}$ Institute of Gerontology, University of Michigan, Ann Arbor, Michigan
}

\begin{abstract}
BACKGROUND. Despite clinical associations and in vitro data suggesting that autocrine interleukin-6 (IL-6) production contributes to prostate cancer progression or chemotherapy resistance, there have been no reports that explore the role of IL-6 on prostate tumors in vivo. In the present study, we investigated the effect of IL-6 inhibition on the growth of human prostate cancer xenografts in nude mice.

METHODS. To determine if autocrine IL-6 production contributes to prostate cancer growth and chemotherapy resistance in vivo, xenografts of a human prostate cancer cell line that produces IL-6 (PC-3) were established in nude mice. The mice were randomly divided into four treatment groups: (1) saline (vehicle control) + murine IgG (isotype control); (2) etoposide + murine IgG; (3) saline + anti-IL-6 monoclonal antibody; and (4) etoposide + antiIL-6 monoclonal antibody. Tumors were measured twice weekly during a 4-week treatment period. At the conclusion of the study, all mice were sacrificed, and in addition to final volume, tumors were evaluated for the degree of apoptosis by TUNEL analysis.

RESULTS. Anti-IL-6 Ab (with saline or etoposide) induced tumor apoptosis and regression ( $\sim 60 \%$ compared to initial tumor size). Etoposide alone did not induce tumor regression or apoptosis in this animal model, and there was no synergy between anti-IL-6 $\mathrm{Ab}$ and etoposide. CONCLUSIONS. These studies suggest that IL-6 contributes to prostate cancer growth in vivo, and that targeting IL-6 may contribute to prostate cancer therapy. Prostate 48:47-53, 2001 (C) 2001 Wiley-Liss, Inc.
\end{abstract}

KEY WORDS: cytokine; interleukin-6; antibody; prostate cancer; chemotherapy

\section{INTRODUCTION}

Prostate cancer is the most common cancer diagnosed in men and the second leading cause of cancer death among men in the United States. In 1999, it was estimated that 179,300 patients were diagnosed with prostate cancer, and 37,000 patients died from the disease [1]. Radical prostatectomy can be curative in patients with localized prostate cancer. Unfortunately, many patients have an advanced form of the disease at the time of diagnosis, and require systemic androgenablation therapy. Initially the cancer appears as an androgen-sensitive phenotype and is responsive to this treatment. However, after a median time of 12-18 months, it commonly recurs as a hormone-refractory phenotype that is also resistant to other therapeutic

Grant sponsor: USAMRMC Prostate Cancer Research Program; Grant number: DAMD17-00-1-053; Grant sponsor: National Institutes of Health; Grant numbers: T32 RR07008 and SPORE 1 P50 CA69568.

*Correspondence to: Evan T. Keller, DVM, Ph.D, Unit for Laboratory Animal Medicine, and Department of Pathology, University of Michigan School of Medicine, 1500 E. Medical Ctr. Dr., Ann Arbor, MI 48109-0940. E-mail: etkeller@umich.edu

Received 18 December 2000; Accepted 2 March 2001 
modalities including chemotherapy [2]. The precise mechanism of drug resistance in prostate cancer is not fully understood, but the secretion of protective factors by these tumors may play a role.

The cytokine interleukin-6 (IL-6) has been implicated in a number of pathophysiologic processes including stimulation of tumor proliferation [3]. In the past few years, evidence has been accumulating that IL-6 may contribute to the progression of prostate cancer [4]. For example, IL-6 serum levels are correlated with morbidity and tumor burden of prostate cancer patients [5]. Furthermore, the addition of anti-IL- 6 antibody to the growth medium of androgen-independent prostate cancer cell lines has been shown to inhibit cell growth [6,7]. Additionally, inhibition of IL-6 activity enhances the cytotoxic activity of certain chemotherapeutic agents in prostate cancer cell lines that are resistant to the drugs [8]. In spite of the many studies demonstrating that IL-6 promotes prostate cancer proliferation and survival in cell culture, there has been no in vivo evidence to confirm that IL-6 contributes to prostate cancer growth. Accordingly, to determine if IL-6 contributes to prostate cancer progression, we examined the effect of inhibiting IL- 6 activity on prostate cancer progression in mice implanted with a human prostate cancer xenograft.

\section{MATERIALS AND METHODS}

\section{Cell Lines}

The hormone-independent prostatic carcinoma cell lines PC-3 and DU145, and the hormone-dependent cell line, LNCaP (ATCC) were cultured in complete medium (RPMI 1640 with L-glutamine supplemented with $10 \%$ heat-inactivated fetal bovine serum, and $1 \%$ penicillin/streptomycin solution containing 10,000 units/ml penicillin $\mathrm{G}$ and 10,000 $\mu \mathrm{g} / \mathrm{ml}$ streptomycin). All three cell lines were grown in a humidified incubator at $37^{\circ} \mathrm{C}$ in $5 \% \mathrm{CO}_{2}$. Cells were treated with trypsin-EDTA, washed, and resuspended in complete medium prior to their use in cytotoxicity assays.

\section{Antibodies}

Anti-hIL-6 (CLB, Amsterdam, The Netherlands) antibody is a mouse monoclonal (subtype IgG1) specific for human IL-6 [9]. Mouse IgG1 ${ }_{k}$ (Sigma, St. Louis, $\mathrm{MO})$ was used as an isotype control antibody.

\section{Etopsoide}

Etoposide (Sigma) was dissolved in $1 \mathrm{ml}$ DMSO to a final stock concentration of $25 \mathrm{mg} / \mathrm{ml}$ and stored at $4^{\circ} \mathrm{C}$. The stock solution was diluted to the indicated concentrations in complete medium (in vitro experiments) or normal saline (in vivo experiments) immediately prior to use.

\section{IL-6 Measurements in Cell Culture}

Cells were grown in 10-cm polystyrene tissue culture dishes. Confluent cells were washed once with phosphate-buffered saline and then incubated for 48$\mathrm{hr}$ in complete medium, at which time the supernatant was collected and stored at $-20^{\circ} \mathrm{C}$ until assayed. IL-6 concentration was measured using a commercial ELISA kit (Quantikine Human IL-6 ELISA Kit; R\&D, Systems Inc., Minneapolis, MN) as directed by the manufacturer.

In some cases, IL-6 levels were measured following the addition of anti-IL6 antibody. In these instances, cells were plated in 6-well polystyrene tissue culture plates at a density of $5 \times 10^{5} /$ well in $2.5-\mathrm{ml}$ complete medium. Anti-IL6 monoclonal antibody, isotype control (final concentration of $500 \mathrm{ng} / \mathrm{ml}$ ), or complete medium was added to appropriate wells and cells were incubated at $37^{\circ} \mathrm{C}$. Supernatant samples were collected from each well at 24,48 , and $72 \mathrm{hr}$ and stored at $-20^{\circ} \mathrm{C}$ until ELISA was performed.

\section{Serum IL- 6 Levels}

At the time of sacrifice, blood samples were collected via cardiac puncture and centrifuged at 2,700 rpm for $10 \mathrm{~min}$. The serum was removed from each sample and stored at $-80^{\circ} \mathrm{C}$ until assayed for IL- 6 using the B9 cell IL-6 bioassay as previously described [10].

\section{In Vitro Cytotoxicity Experiments}

Cell lines were seeded in 96-well plates at a density of $2 \times 10^{3}$ cell/well in 100- $\mu 1$ complete medium. Either anti-IL6 or isotype control antibody was added at a concentration of $2 \mu \mathrm{g} / \mathrm{ml}$ (final concentration to be 500 $\mathrm{ng} / \mathrm{ml})$ in $50 \mu \mathrm{l}$ of complete medium, and etoposide was added in a $50-\mu \mathrm{l} /$ volume to reach a final concentration of 0.1 or $10 \mu \mathrm{g} / \mathrm{ml}$ (approximate $\mathrm{ID}_{25}$ and $\mathrm{ID}_{50}$, respectively; data not shown). Saline vehicle was added to cells that did not receive etoposide. The cells were then incubated for $48 \mathrm{hr}$. Cell viability was then determined using an MTS assay (Promega, Madison, WI) as directed by the manufacturer. Cytotoxicity was calculated as follows:

$$
\begin{aligned}
\% \text { cytotoxicity }= & {[1-(\text { absorbance of experimental }} \\
& \text { wells } / \text { absorbance of control } \\
& \text { wells })] \times 100 .
\end{aligned}
$$




\section{Mice}

Eight-week-old nude (nu/nu) mice (Charles River Laboratories, Wilmington, MA) were kept in a specific pathogen free colony, in microisolator cages, and were fed sterile rodent chow and sterile water ad libitum. All protocols were approved by the University of Michigan Animal Care and Use Committee.

\section{In Vivo Experiments}

Confluent PC-3 cells were harvested by trypsinzation, washed twice with PBS and resuspended at a density of $1 \times 10^{7}$ cells $/ \mathrm{ml}$. The mice were injected subcutaneously with $100 \mu \mathrm{l}$ of the tumor cell suspension $\left(10^{6}\right.$ cells $)$ combined with $100 \mu \mathrm{l}$ of Matrige ${ }^{\mathbb{B}}$ (Bectin-Dickson, Bedford, MA). The mice were monitored for tumor growth, and when tumors were detected by palpation, measurement of the tumors began. Tumor volumes were calculated by the formula: Volume $=\left[(\text { minimum measurement })^{2}\right.$ (maximum measurement)] $\div 2$ [as described in Ref. [11]]. Tumors were measured every other day, and when tumors reached a volume of $126 \mathrm{~mm}^{3}$ the mice were randomly assigned to one of four treatment groups $(n=10 /$ group). Treatment groups included isotype + saline, isotype + etoposide, anti-IL-6 + saline, and anti-IL-6 + etoposide. The treatment regimen consisted of weekly i.p. injection of anti-IL6 or isotype antibody at $500 \mu \mathrm{g} /$ mouse/week as previously described [12] and daily i.p. injections of etoposide at $50 \mathrm{mg} / \mathrm{m}^{2} /$ day, which is the human-equivalent dose [13], or an equal volume of saline. Mouse IL-6 does not react with human IL-6 receptor [14]. Thus, using an anti-human-IL-6 alone will inhibit the IL-6 specifically produced by the human prostate cancer cells. Treatment continued for 4 weeks, during which time the tumors were measured on a twice-weekly basis. At the conclusion of the study all mice were sacrificed, and blood and tissue samples were collected for further analysis.

\section{Tumor Histopathology and Detection of Apoptosis}

Excised tumors were placed in 10\% formalin, embedded in paraffin and sectioned at $10 \mu \mathrm{M}$ thickness. Sections were examined utilizing standard hematoxylin and eosin (H\&E) staining for routine histopathology. To evaluate apoptosis, sections were deparaffinized, rehydrated, and subjected to terminal deoxytransferase UTP end-labeling (TUNEL) analysis using ApopTag ${ }^{\circledR}$ Plus Peroxidase Kit (Intergen, Purchase, NY) according to the manufacturer's directions. The number of apoptotic nuclei per 200X field (averaged from three random 200X fields) was determined for each section by an investigator that was blinded to the samples as previously described [15].

\section{Statistical Analysis}

To determine differences among treatment groups for tumor size, two-way analysis of variance (ANOVA) was used followed by Fisher's least significant difference for post-hoc analysis. Statistical significance was determined at $P<0.05$.

\section{RESULTS}

\section{IL- 6 Secretion by Prostate Cancer Cell Lines}

The detection of IL-6 secretion by prostate cancer cell lines is fairly inconsistent between laboratories $[6,7,16]$. Thus, it was critical to determine the IL-6 expression of various cell lines in our laboratory prior to proceeding with an in vivo challenge. Accordingly, we measured the amount of IL-6 secreted into the culture supernatant of various prostate cancer cell lines. PC-3 cells secreted the most IL- 6 followed by DU-145 cells (Fig. 1A). IL-6 was undetectable in LNCaP cell culture supernatant (Fig. 1A).

\section{Effect of IL- 6 Antibody Treatment on IL- 6 Levels in PC-3 Cell Culture Supernatant}

In order to provide a maximum challenge to our ability to inhibit IL-6, we performed the remaining experiments with the PC-3 cells, which secreted the highest levels of IL-6. To confirm that the anti-IL-6 antibody we were using effectively inhibited IL-6 levels over a length of time, we incubated PC-3 cells with $500 \mathrm{ng} / \mathrm{ml}$ of either anti-IL-6 or isotype control antibody for 24, 48, and $72 \mathrm{hr}$, then measured IL-6 levels using ELISA. Anti-IL- 6 antibody decreased the detection of IL- 6 by $\geq 50 \%$ at all three time points compared to the isotype antibody (Fig. 1B).

\section{Effect of Anti-IL- 6 and Etoposide on Cell Proliferation of PC-3 Cells}

To determine if anti-IL-6 antibody enhances the etoposide-mediated cytotoxicity of prostate cancer cells, we incubated prostate cancer cells with antibody and etoposide, then measured viable cell number. Anti-IL-6 antibody alone decreased the number of viable cells by approximately $10 \%$ (Fig. 2). Etoposide alone at low $(0.1 \mu \mathrm{M})$ and high $(10 \mu \mathrm{M})$ doses induced approximately 5\% cytotoxicity. AntiIL-6 antibody combined with the high dose of etoposide induced approximately $25 \%$ cytotoxicity, thus demonstrating a synergistic effect between etoposide and anti-IL-6 antibody in vivo. These in vitro data provided the rationale to pursue the ability of IL-6 antibody to modulate prostate cancer cell growth in vivo. 
A.

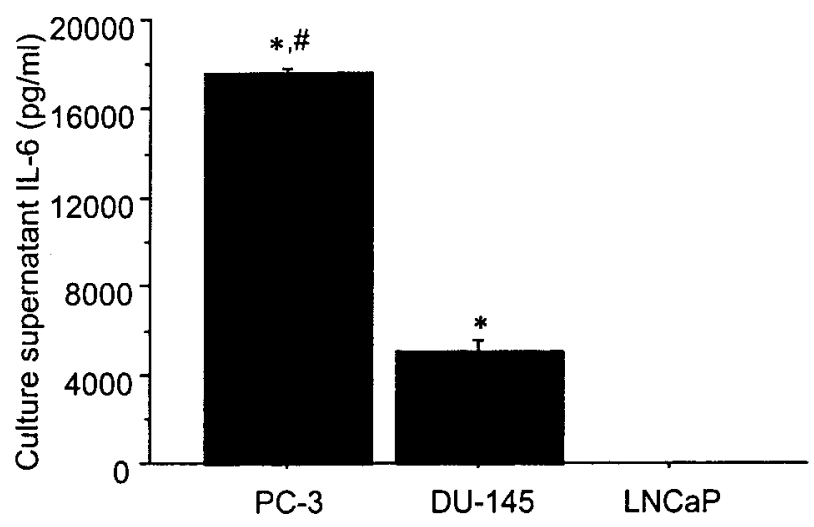

B.

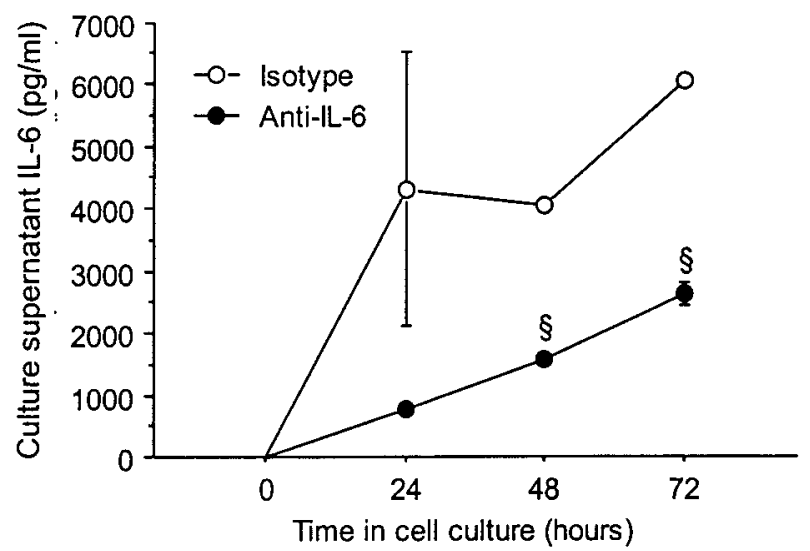

Fig. I. Anti IL- 6 antibody diminished ELISA detectable IL- 6 from PC-3 cells. A:The indicated prostate cancer cell lines were plated at a density of $5 \times 10^{6}$ cells $/ 10 \mathrm{ml}$ in $10 \mathrm{~cm}$ tissue culture plates and cultured for $48 \mathrm{hr}$. Supernatant was then collected and subjected to ELISA for IL-6. B: PC-3 cells were plated in 6 -well polystyrene tissue culture plates at a density of $5 \times 10^{5} /$ well in $2.5 \mathrm{ml}$ complete medium. Anti-IL- 6 monoclonal antibody or isotype control (final concentration of $500 \mathrm{ng} / \mathrm{ml}$ ) was added and cells were incubated at $37^{\circ} \mathrm{C}$. Supernatant samples were collected from each well at 24, 48, and $72 \mathrm{hr}$ and subjected to ELISA for IL-6. All time points were run on the same plate. Both assays were performed in triplicate. ${ }^{*} P<0.01$ vs. LNCaP, ${ }^{\#} P<0.01$ vs. DU-145, ${ }^{\circledR} P<0.05$ vs. isotype.

\section{Tumor Response}

Based on our observation that inhibition of IL-6 alone inhibited PC-3 survival in addition to enhancing-mediated cytotoxicity in vivo, we next explored if inhibiting IL-6 would mimic these effects in vivo on established prostate cancer tumors. To accomplish this, PC-3 cells were subcutaneously injected into nude mice. The tumors were allowed to develop until they were approximately $126 \mathrm{~mm}^{3}$, at which time anti-IL-6 or isotype antibody and etoposide administration was initiated. Antibody was administered at a level that inhibited IL-6 bioactivity by approximately $20 \%$ (based on B9 bioassay; data not shown). Treatment

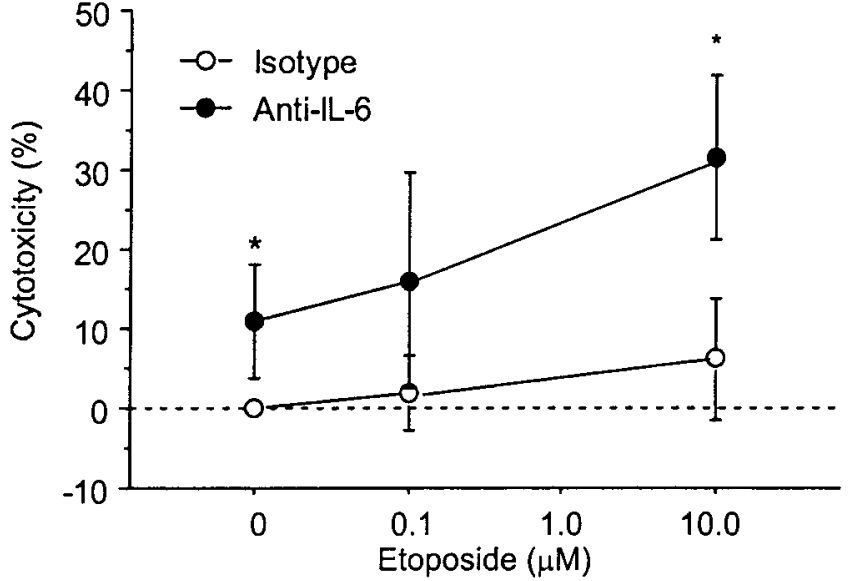

Fig. 2. Inhibition of IL-6 induces cytotoxicity of PC-3 cells in vitro. Cell lines were seeded in 96 -well plates at a density of $2 \times 10^{3}$ cells/well in $100 \mu \mathrm{l}$ complete medium. Either anti-IL6 or isotype control antibody was added at a concentration of $2 \mu \mathrm{g} / \mathrm{ml}$ (final concentration to be $500 \mathrm{ng} / \mathrm{ml}$ ) in $50 \mu \mathrm{l}$ of complete medium. Etoposide was added in a $50 \mu \mathrm{l} /$ volume to reach a final concentration of $0.1 \mu \mathrm{g} / \mathrm{ml}$ or $10 \mu \mathrm{g} / \mathrm{ml}$ (approximate $\mathrm{ID}_{25}$ and $\mathrm{ID}_{50}$, respectively; data not shown). Saline vehicle was added to wells not receiving etoposide. The cells were then incubated for $48 \mathrm{hr}$. Cell viability was then determined using an MTS assay and cytotoxicity was determined as described in the Methods section. The assay was performed in triplicate $* P<0.05$ vs. isotype.

was continued for a 4-week period. Using an ELISA specific for human IL-6 (and non-cross-reactive with murine IL-6), we determined that serum human IL-6 levels were $30.1 \pm 10.4 \mathrm{pg} / \mathrm{ml}$ in tumor-implanted saline + isotype control mice, compared to undetectable levels in mice not implanted with tumor, demonstrating that the tumors produced IL-6 in vivo. The tumors in the isotype-treated mice had a continuous, albeit slow, tumor growth rate, whereas the tumors in the istotype + etoposide-treated mice did not grow (Fig. 3). In contrast, the final tumor volumes were reduced by approximately $60 \%$ compared to their initial size in the mice receiving anti-IL-6 or anti-IL6 + etoposide. Furthermore, they were approximately $75 \%$ smaller than the tumors in the mice receiving isotype alone (Fig. 3). There was no significant difference between the tumor volumes in the mice treated with istotype alone compared to the mice treated with etoposide alone.

\section{Apoptosis}

We evaluated the effect of anti-IL-6 antibody and etoposide on the amount of apoptosis present in the PC-3 tumors. Routine histological evaluation of the tumors did not demonstrate any differences among the treatment groups. However, administration of anti-IL-6 antibody was associated with marked apop- 


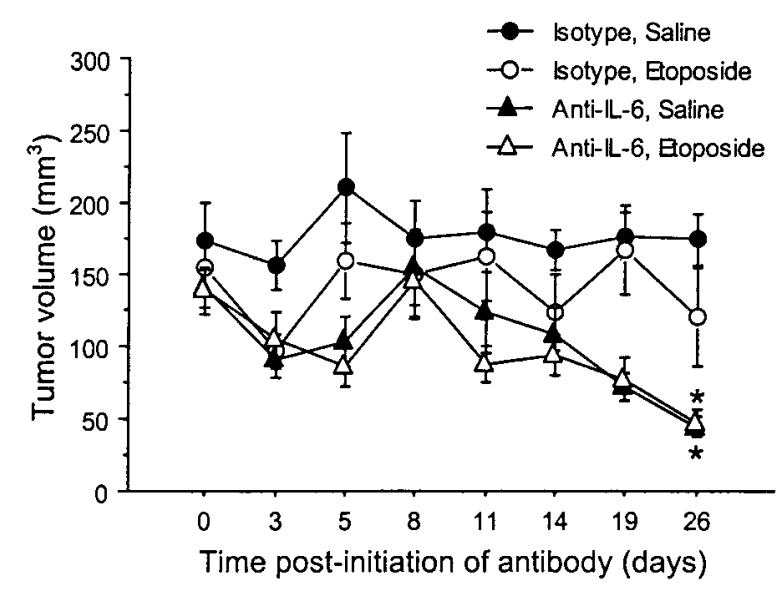

Fig. 3. Inhibition of IL- 6 induces PC- 3 xenograft regression in mice. PC-3 cells $\left(10^{6}\right)$ in a Matrigel slurry were subcutaneously implanted in male nu/nu mice. When tumors reached $126 \mathrm{~cm}^{3}$, weekly i.p. injections of anti-IL6 or isotype antibody $(500 \mu \mathrm{g} /$ mouse) and daily i.p. injections of etoposide $\left(50 \mathrm{mg} / \mathrm{m}^{2}\right)$ or saline vehicle were initiated. Tumors were measured twice-weekly for 4 weeks. There were 10 animals/group. Results are shown as mean $\pm S D$. $* P<0.0$.

tosis in the tumors from both the saline vehicle and etoposide treated mice, compared to the moderate level of apoptosis in the tumors from the isotype and isotype + etoposide-treated mice (Fig. 4). These data demonstrate that IL-6 has an anti-apoptotic action in PC-3 cells in vivo.

\section{DISCUSSION}

A large body of evidence has accumulated that suggests IL-6 contributes to prostate cancer progression. The evidence includes both clinical observations that increased levels of IL-6 are associated with increasing grade of prostate cancer in patients $[5,17,18]$ and in vitro experiments that have demonstrated that IL-6 promotes prostate cancer cell growth and prevents chemotherapeutic-mediated cytotoxicity $[7,19]$. In the current study, we provide the first demonstration that IL-6 activity promotes prostate cancer growth in vivo.

Our data demonstrate that high levels of IL-6 are secreted by PC-3 and DU-145 cells, whereas IL-6 levels were not detectable using ELISA methodology in LNCaP cells. These findings are consistent with previous reports on IL-6 secretion by prostate cancer cell lines [6,8]. PC-3 and DU-145 cells are androgen non-responsive, whereas $\mathrm{LNCaP}$ cells are androgen-responsive. Thus, these results suggest that loss of androgen responsiveness is associated with increased IL-6 expression. This postulation is consistent with the observations that elevation of serum IL-6 levels is associated with increasing grade of prostate cancer $[5,18,20]$. A cause and effect cannot be determined based on the current data. However, it has been previously reported that the androgen dihydrotestosterone inhibits IL-6 expression in prostate cancer cells [16] and that orchiectomy increased IL-6 expression in murine bone marrow [10]. Thus, it is plausible that loss of androgen-response promotes IL-6 expression.

Prostate cancer is poorly responsive to chemotherapy. Therefore, a mechanism to enhance chemotherapeutic killing of tumors would be a boon for prostate cancer patients. Borsellino et al. [7] have reported that inhibition of IL-6 activity enhances chemotherapeutic killing of prostate cancer cell in vitro. However, this effect has not been reported in vivo. In the current study, the cell type and therapeutic agent were chosen based on in vitro studies, and the human equivalent dose of etoposide was used to calculate the dosage administered to the mice. However, we did not observe an effect of etoposide on the PC-3 in vivo. In contrast, tumors responded to anti-IL-6 antibody, although the combination of anti-IL-6 and etoposide did not significantly enhance this inhibitory effect compared to anti- 6 alone. Taken together, these data suggest that inhibition of IL-6 does not enhance etoposide-mediated killing in vivo. However, they clearly demonstrate that inhibition of IL-6 alone, or in the presence of etoposide, induces regression of PC-3 tumors. This observation provides in vivo evidence that IL-6 contributes to prostate cancer cell growth, and that inhibition of its activity promotes tumor regression.

This ability to inhibit IL-6 activity in humans has been previously demonstrated in several clinical trials using murine monoclonal antibodies in patients with multiple myeloma [21,22]. Early trials demonstrated the feasibility of blocking IL-6 activity in this manner, and that such therapy had beneficial effects [21]. These trials also revealed certain limitations to anti-IL-6 therapy using murine monoclonal antibodies. One such limitation is that in some patients with advanced disease, IL-6 levels were so high that the antibody was unable to neutralize them [22]. Another limitation is that development of antibodies to mouse immunoglobulin may result in rapid clearance of the murine monoclonal antibody and diminished efficacy of treatment [23]. This problem has been addressed through the chimerization $[23,24]$ and humanization [24] of murine anti-IL-6 antibodies. Tsunenari et al. [24] demonstrated reduced antigenicity of chimeric antibodies and even lower antigenicity of humanized murine antibodies (24) while a later study by van Zaanen et al. [23] showed no induction of human antichimeric antibodies in multiple myeloma patients receiving chimeric anti-IL-6 antibodies. Overall, these studies suggest that inhibition of IL-6 activity in prostate cancer patients is achievable. 

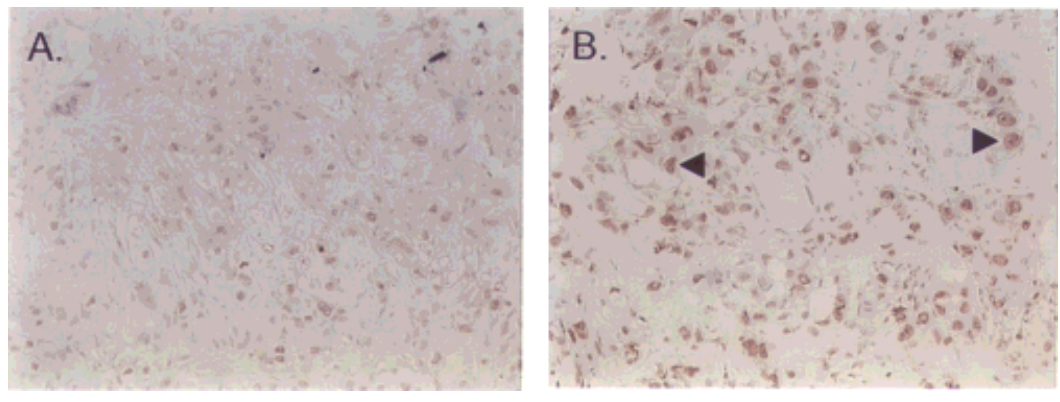

C.

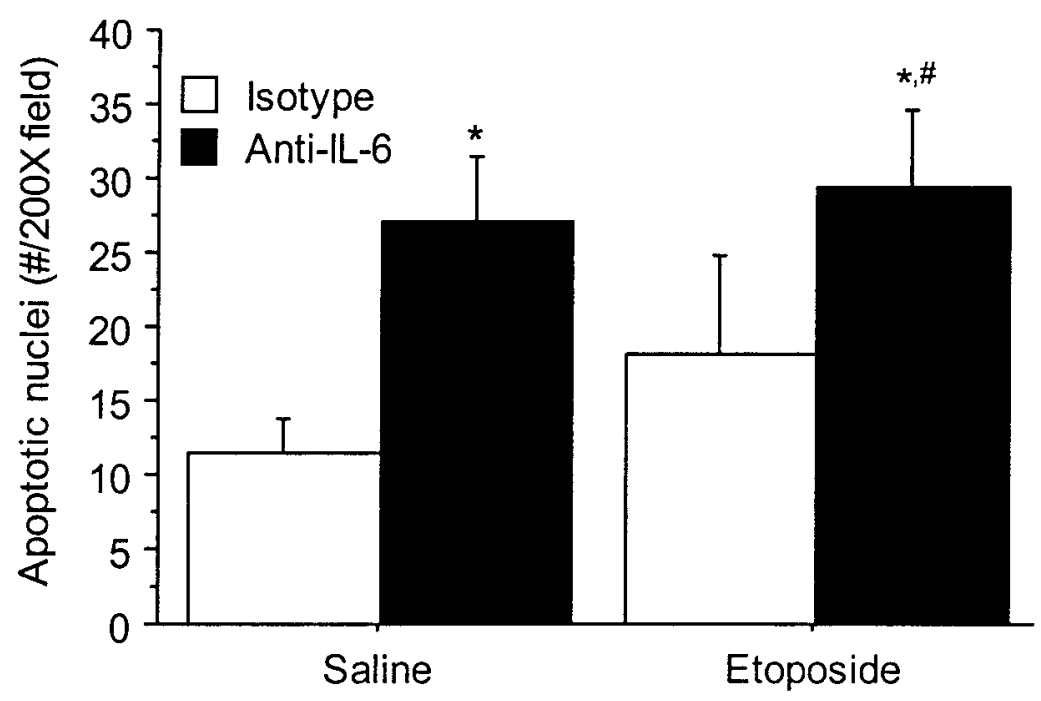

Chemotherapeutic

Fig. 4. Inhibition of IL- 6 induces apoptosis in PC-3 tumors in mice. Tumors were excised from mice 4 weeks after initiation of anti-IL6 and etoposide as described in Fig. 3. Breaks in DNA were determined by labeling $3^{\prime} \mathrm{OH}$ termini using terminal deoxytransferase and staining with peroxidase. Tumor sections are shown from (A) isotype-treated mice and (B) anti-IL- 6 treated mice. Apoptotic nuclei are dark brown (arrowheads). Original magnification $100 \times$.C: To determine the degree of apoptosis, the number of apoptotic nuclei/ $200 \times$ field (average of triplicate) were determined by an investigator blinded to the samples. $* P<0.01$ compared to the saline + isotype mice; $* P<0.05$ compared to the etoposide + isotype mice. Data are shown as mean \pm SD of 4 mice/group.

The mechanism through which IL-6 contributes to overall prostate tumor growth is not clear. There are conflicting reports regarding the effect of IL-6 on prostate cancer cell proliferation in vitro [4]. Thus, it is unclear if IL-6 directly contribute to tumor growth through stimulation of cell proliferation. In addition to increased cell proliferation, a tumor may enlarge due to decreased apoptotic death of cell. The observation that IL-6 has been demonstrated to have anti-apoptotic action in several cell types $[19,25,26]$ including the prostate cancer cell lines LNCaP and PC-3 (27) led us to evaluate IL-6's effect on apoptosis in the prostate cancer xenografts. Our observation that the level of apoptosis in tumors of mice that received anti-IL-6 compared to those who received isotype control antibody demonstrates that IL-6 protects prostate cancer cells from apoptosis in vivo. These findings are consistent with the in vitro results of Chung et al. [27] who demonstrated the antiapoptotic effects of IL-6 in PC-3 and LNCaP cell lines, and showed that this effect is the result of IL-6 activation of phosphatidylinositol (PI)-3 kinase. These previous reports, taken together with the currently reported murine studies, suggest that inhibition of apoptosis is one mechanism through which IL-6 contributes to prostate cancer progression.

\section{CONCLUSION}

In summary, the current study demonstrates that anti-IL-6 antibody induces apoptosis and regression of established PC-3 tumors in mice. However, the in vivo 
data do not support the in vitro observations that IL-6 enhances etoposide-mediated killing. These data, combined with the clinical reports that IL-6 is associated with prostate cancer stage $[17,18,28]$, provide compelling evidence that IL-6 contributes to prostate cancer progression and suggests that targeting IL-6 may induce prostate cancer regression.

\section{REFERENCES}

1. Landis SH, Murray T, Bolden S, Wingo PA. Cancer statistics, 1999. CA Cancer J Clin 1999;49(1):1,8-31.

2. Mahler C, Denis L. Management of relapsing disease in prostate cancer. Cancer 1992;70(1 Suppl):329-334.

3. Keller ET, Wanagat J, Ershler WB. Molecular and cellular biology of interleukin-6 and its receptor. Front Biosci 1996;1:340357.

4. Smith PC, Hobisch A, Lin DL, Culig Z, Keller ET. Interleukin-6 and prostate cancer progression. Cytokine Growth Factor Rev 2001;12(1):33-40

5. Twillie DA, Eisenberger MA, Carducci MA, Hseih WS, Kim WY, Simons JW. Interleukin-6: A candidate mediator of human prostate cancer morbidity. Urology 1995;45(3):542-549.

6. Chung TD, Yu JJ, Spiotto MT, Bartkowski M, Simons JW. Characterization of the role of IL- 6 in the progression of prostate cancer. Prostate 1999;38(3):199-207.

7. Borsellino N, Belldegrun A, Bonavida B. Endogenous interleukin 6 is a resistance factor for cis-diamminedichloroplatinum and etoposide-mediated cytotoxicity of human prostate carcinoma cell lines. Cancer Res 1995;55(20):4633-4639.

8. Borsellino N, Bonavida B, Ciliberto G, Toniatti G, Travali S, $\mathrm{D}^{\prime}$ Alessandro N. Blocking signaling through the Gp130 receptor chain by interleukin- 6 and oncostatin M inhibits PC-3 cell growth and sensitizes the tumor cells to etoposide and cisplatinmediated cytotoxicity. Cancer 1999;85(1):134-144.

9. Brakenhoff JP, Hart M, De Groot ER, Di Padova F, Aarden LA. Structure-function analysis of human IL-6. Epitope mapping of neutralizing monoclonal antibodies with amino- and carboxylterminal deletion mutants. J Immunol 1990;145(2):561-568.

10. Zhang J, Pugh TD, Stebler B, Ershler WB, Keller ET. Orchiectomy increases bone marrow interleukin-6 levels in mice. Calcif Tissue Int 1998;62(3):219-226.

11. Davol PA, Frackelton AR, Jr. Targeting human prostatic carcinoma through basic fibroblast growth factor receptors in an animal model: characterizing and circumventing mechanisms of tumor resistance. Prostate 1999;40(3):178-191.

12. Finck BK, Chan B, Wofsy D. Interleukin 6 promotes murine lupus in NZB/NZW F1 mice. J Clin Invest 1994;94(2):585-591.

13. Pienta KJ, Lehr JE. Inhibition of prostate cancer growth by estramustine and etoposide: Evidence for interaction at the nuclear matrix. J Urol 1993;149(6):1622-1625.

14. Leebeek FW, Fowlkes DM. Construction and functional analysis of hybrid interleukin- 6 variants. Characterization of the role of C-terminus for species specificity. FEBS Lett 1992;306(2-3): 262-264.

15. Liefer KM, Koster MI, Wang XJ, Yang A, McKeon F, Roop DR. Down-regulation of p63 is required for epidermal UV-Binduced apoptosis. Cancer Res 2000;60(15):4016-4020.
16. Keller ET, Chang C, Ershler WB. Inhibition of NFkappaB activity through maintenance of IkBa levels contributes to dihydrotestosterone-mediated repression of the interleukin-6 promoter. J Biol Chem 1996;271(42):26267-26275.

17. Akimoto S, Okumura A, Fuse H. Relationship between serum levels of interleukin-6, tumor necrosis factor-alpha and bone turnover markers in prostate cancer patients. Endocrind J 1998; 45(2):183-189.

18. Adler HL, McCurdy MA, Kattan MW, Timme TL, Scardino PT, Thompson TC. Elevated levels of circulating interleukin- 6 and transforming growth factor-betal in patients with metastatic prostatic carcinoma. J Urol 1999;161(1):182-187.

19. Chen RH, Chang MC, Su YH, Tsai YT, Kuo ML. Interleukin-6 inhibits transforming growth factor-beta-induced apoptosis through the phosphatidylinositol 3-kinase/Akt and signal transducers and activators of transcription 3 pathways. J Biol Chem 1999;274(33):23013-23019.

20. Drachenberg DE, Elgamal AA, Rowbotham R, Peterson M, Murphy GP. Circulating levels of interleukin-6 in patients with hormone refractory prostate cancer. Prostate 1999;41(2):127133.

21. Klein B, Wijdenes J, Zhang XG, Jourdan M, Boiron JM, Brochier J, Liantard J, Merlin M, Clement C, Morel-Fournier B. Murine anti-interleukin-6 monoclonal antibody therapy for a patient with plasma cell leukemia. Blood 1991;78(5):1198-1204.

22. Bataille R, Barlogie B, Lu ZY, Rossi JF, Lavabre-Bertrand T, Beck $\mathrm{T}$, Wijdenes J, Brochier J, Klein B. Biologic effects of antiinterleukin-6 murine monoclonal antibody in advanced multiple myeloma. Blood 1995;86(2): 685-691.

23. van Zaanen HC, Lokhorst HM, Aarden LA, Rensink HJ, Warnaar SO, van der Lelie J, van Oers MH. Chimaeric antiinterleukin 6 monoclonal antibodies in the treatment of advanced multiple myeloma: A phase I dose-escalating study. Br J Haematol 1998; 102(3):783-790.

24. Tsunenari T, Akamatsu K, Kaiho S, Sato K, Tsuchiya M, Koishihara Y, Kishimoto T, Ohsugi Y. Therapeutic potential of humanized anti-interleukin-6 receptor antibody: antitumor activity in xenograft model of multiple myeloma. Anticancer Res 1996;16(5A):2537-2544.

25. Dedoussis GV, Mouzaki A, Theodoropoulou M, Menounos P, Kyrtsonis MC, Karameris A, Maniatis A. Endogenous interleukin 6 conveys resistance to cis-diamminedichloroplatinummediated apoptosis of the K562 human leukemic cell line. Exp Cell Res 1999;249(2):269-278.

26. Atreya R, Mudter J, Finotto S, Mullberg J, Jostock T, Wirtz S, Schutz M, Bartsch B, Holtmann M, Becker C, Strand D, Czaja J, Schlaak JF, Lehr HA, Autschblach F, Schurmann G, Nishimoto N, Yoshizaki K, Ito H, Kishimoto T, Galle PR, Rose-John S, Neurath MF. Blockade of interleukin 6 trans signaling suppresses T-cell resistance against apoptosis in chronic intestinal inflammation: Evidence in Crohn disease and experimental colitis in vivo. Nat Med 2000;6(5):583-588.

27. Chung TD, Yu JJ, Kong TA, Spiotto MT, Lin JM. Interleukin-6 activates phosphatidylinositol-3 kinase, which inhibits apoptosis in human prostate cancer cell lines. Prostate 2000;42(1): $1-7$.

28. Hobisch A, Rogatsch H, Hittmair A, Fuchs D, Bartsch G, Jr., Klocker H, Bartsch G, Culig Z. Immunohistochemical localization of interleukin-6 and its receptor in benign, premalignant and malignant prostate tissue. J Pathol 2000;191(3):239-244. 